\title{
Inhalation Exposure and Respiratory Protection of Home Healthcare Workers Administering Aerosolized Medications (Simulation Study)
}

\author{
Katherine Ollier ${ }^{1}$, Maija Leppänen ${ }^{1,2}$, Bingbing $\mathrm{Wu}^{1}$, Michael Yermakov ${ }^{1}$, \\ Nicholas C. Newman ${ }^{1,3}$, Tiina Reponen ${ }^{1}$, Sergey A. Grinshpun ${ }^{1 *}$ \\ ${ }^{1}$ Center for Health-Related Aerosol Studies, Department of Environmental Health, College of Medicine, University of \\ Cincinnati, Cincinnati, OH 45267-0056, USA \\ ${ }^{2}$ On leave from University of Eastern Finland, Department of Environmental and Biological Sciences, 70211 Kuopio, \\ Finland \\ ${ }^{3}$ Department of Pediatrics, College of Medicine, University of Cincinnati, Cincinnati, OH 45229, USA
}

\begin{abstract}
There is little information regarding aerosol exposure from using medical nebulizers and the factors affecting the risk of exposure, especially for treatments performed in a patient's home environment. Home healthcare workers (HHWs) are a rapidly growing work population often exposed to aerosol hazards. Thus, we designed a simulated environment to measure the aerosol inhalation exposure of an HHW administering pressure-nebulized medications. We determined the relative contributions of different factors to aerosol reduction, namely, the room air exchange rate, proximity to the patient, and patient breathing rate, in an exposure chamber simulating a patient's bedroom. Additionally, the performance of respiratory protective devices worn by an HHW, a surgical mask and N95 filtering facepiece respirator (FFR), was evaluated using $\mathrm{NaCl}$ as a well-established surrogate. The particle concentration in the breathing zone of an unprotected worker ranged from 7,118 to $284,600 \mathrm{~cm}^{-3}$. The proximity to the aerosol source affected the aerosol concentration, but the influence of this factor diminished when the distance increased beyond 24 inches. For an unprotected HHW, ventilation was the most effective way to reduce exposure to nebulizer-produced medical aerosols. An increase in the air exchange rate from 0 to $5 \mathrm{~h}^{-1}$ significantly reduced the exposure; however, a further increase (to $17 \mathrm{~h}^{-1}$ ) produced only a small reduction in the particle concentration. Therefore, no evidence suggests that patient homes require extremely efficient ventilation to mitigate HHWs' exposure to nebulizer-produced medications. Increasing the patient's breathing flow rate reduced the aerosol inhalation exposure; however, this factor cannot be controlled, which weakens its practical viability. Wearing respiratory protection devices was found to be the most efficient way to reduce aerosol exposure (within the set of tested variables). As expected, an N95 FFR with a proper seal was about 20-fold more efficient than a surgical mask.
\end{abstract}

Keywords: Aerosol exposure; Medical nebulizer; Respiratory protection; Home healthcare.

\section{INTRODUCTION}

Healthcare professionals working in hospitals can come into close contact with numerous types of occupational hazards such as exposure to reproductive hazards (Lawson et al., 2012) as well as infectious agents and blood borne pathogens (Veccio et al., 2003). Exposure of healthcare workers to medications, especially when performing treatments involving aerosolized drugs, has the potential for significant reactions, including, but not limited to bronchospasm, allergy, and anaphylaxis (Nicklas, 1990;

\footnotetext{
* Corresponding author.

Tel.: +1-513-558-0504; Fax: +1- 513-558-2263

E-mail address: sergey.grinshpun@uc.edu
}

Riordan and Smaldone, 1992; Bone and Amundson, 1993; Jayaraman and Brar, 2016). Home healthcare workers (HHWs) providing their services in patients' homes do not have the benefit of working in a controlled environment such as a hospital setting. Hospital rooms typically have a high air exchange rate (AER); e.g., surgical suites are often operated at about 20 air exchanges per hour (ASHRAE, 2017). Additionally, hospital rooms are frequently cleaned. In contrast, residential settings typically have relatively low exchange rate or no ventilation at all. Besides the healthcare related exposures, HHWs can also be exposed to household hazards (Sherman et al., 2008; Agbonifo et al., 2017).

One exposure source of the HHWs is the medications that are administered using medical nebulizers, which aerosolize medication intended for patient inhalation, e.g., for asthma and COPD treatment (Campbell, 1999). Some of the most common pressure-nebulized medications are 
ipratropium bromide, budesonide (Elmashae et al., 2018), and albuterol sulfate (Kerwin et al., 2016; Elmashae et al., 2018).

Medical nebulizers are not built to provide a tight fit to a patient under treatment. The facial mask connected to a nebulizer does not have a perfect seal on the patient's face and there is a visible cloud around the patient during treatments. Therefore, an HHW can receive secondhand exposure while administering medication with a nebulizer. Secondhand exposure to inhaled bronchodilators by a healthcare professional has been associated with an increased health risk (Ari et al., 2016). Although home healthcare is one of the fastest growing healthcare fields in the United States (Gershon et al., 2008), very few agencies adequately address occupational aerosol exposure of HHWs and provide respiratory protection training and fit testing to minimize the inhalation exposure of their employees in patient homes (Gershon et al., 2010). It is not uncommon for HHWs to enter a home with no respiratory protection at all. The authors found no guidelines or recommendations from the Occupational Safety and Health Administration (OSHA) or the National Institute for Occupational Safety and Health (NIOSH) that would adequately address the HHWs' exposure to pressure-nebulized medications or require respiratory protection in patients' homes.

There is insufficient information regarding the aerosols that escape from the mask of a medical nebulizer into the patient's room and breathing space of a healthcare worker. The factors affecting the concentration of these particles in a home environment are not characterized. In a pilot laboratory study conducted by our group with a jet-nebulizer, inhalation exposures to the above-listed medications were evaluated (Elmashae et al., 2018). This study was performed in a small chamber simulating a two-dimensional configuration with two manikins, which mimicked a patient and an HHW facing each other. It was concluded that the total aerosol mass concentration in the breathing zone of an HHW could vary from 2.29 to $10.2 \mu \mathrm{g} \mathrm{m}^{-3}$. Conducting the testing under controlled laboratory conditions, this rather simplistic simulation effort could not fully address the environmental conditions affecting the HHW's exposure in a typical home. Another pilot investigation, which was focused on the evaluation of respiratory protective devices used in a home healthcare environment, was carried out under field conditions and involved multiple tasks; however, this effort was not specifically focused on the nebulizer treatments and did not consider variables such as AER (Elmashae et al., 2017).

The present study built on the foundation created by the recent pilot laboratory testing of Elmashae et al. (2018) aims at developing the next level simulation setting to measure the aerosol exposure of an HHW affected by different environmental factors, and to determine the relative contributions of these factors on the aerosol exposure reduction in a room-size chamber. The performance of different respiratory protective devices typically worn by an HHW was also evaluated.

\section{MATERIALS AND METHODS}

\section{Experimental Design}

This simulation study was performed in an exposure chamber $\left(24.3 \mathrm{~m}^{3}\right)$ as presented in Fig. 1. The chamber was equipped with a closed-loop ventilation and air filtration system under three different AERs: 0 (calm air), $5 \mathrm{~h}^{-1}$, and $17 \mathrm{~h}^{-1}$. The calm air represents a home with turned off or non-functioning ventilation, which serves as the worst case scenario from the exposure standpoint. Air exchange rate of $5 \mathrm{~h}^{-1}$ is believed to be a reasonable estimate of a highly efficient residential home ventilation (based on our review of multiple surveys, e.g., those quoted in Reichman et al., 2017). The highest tested rate of $17 \mathrm{~h}^{-1}$ represents the high-air-exchange hospital settings; the AERs listed in the ASHRAE/ANSI/ASHE standard for ventilation of healthcare facilities ranges from $15 \mathrm{~h}^{-1}$ in procedure rooms to $20 \mathrm{~h}^{-1}$ in operating rooms (ASHRAE, 2017). The latter was utilized to compare aerosol exposure levels for an HHW administering a pressure-nebulized medication in a patient's home and a hospital room.

A breathing manikin simulating a patient was placed approximately in the center of the test chamber with a nebulizer mask positioned on the manikin's face using a standardized procedure. A breathing simulator (BRSS, Koken Ltd., Tokyo, Japan) was connected to the manikin via plastic tubing. A HEPA filter was placed between the manikin and breathing simulator. The filter prevented particles inhaled by the manikin from being exhaled and "double-counted" in the breathing zone. The tests were conducted at two breathing conditions of a patient represented by the mean inspiratory flow (MIF) rates of 15 and $30 \mathrm{~L} \mathrm{~min}^{-1}$. The MIF was varied by changing the breathing frequency (from 0.25 to $0.5 \mathrm{~Hz}$ ) with a tidal volume being kept the same $(1 \mathrm{~L})$. The tested MIF values are representative of respiratory rates typically seen in adults and children (Lindh et al., 2009; Barrett et al., 2012; Rodriguez-Molinero et al., 2013).

The test variables are presented in Table 1 below. In addition to the AER and MIF, we varied the proximity of an HHW to the aerosol source (nebulizer), and the level of respiratory protection.

The study protocol was designed so that any exposure to potentially hazardous aerosolized drugs would be avoided. A sodium chloride $(\mathrm{NaCl})$ aerosol was used as a surrogate of nebulized medications commonly administered by HHWs based on the findings reported in our earlier study (Elmashae et al., 2018). Particles were aerosolized by a PARI LC Sprint reusable nebulizer (Model 023F35, PARI Respiratory Equipment Inc., Midlothian, VA, USA) charged with a $0.9 \% \mathrm{NaCl}$ solution. The nebulizer was connected to an adult PARI mask. A Vios PRO compressor ran at $10 \mathrm{~L} \mathrm{~min}^{-1}$ for a minimum of $10-12 \mathrm{~min}$ to reach concentration plateau in the chamber before data collection started for the tests conducted at AER $=5$ and $17 \mathrm{~h}^{-1}$. When testing at no air exchange, it took longer, 15-20 minutes to reach the intended plateau. Typically, nebulizer treatment sessions last between 5 and $10 \mathrm{~min}$, but some may take up to $20 \mathrm{~min}$. 


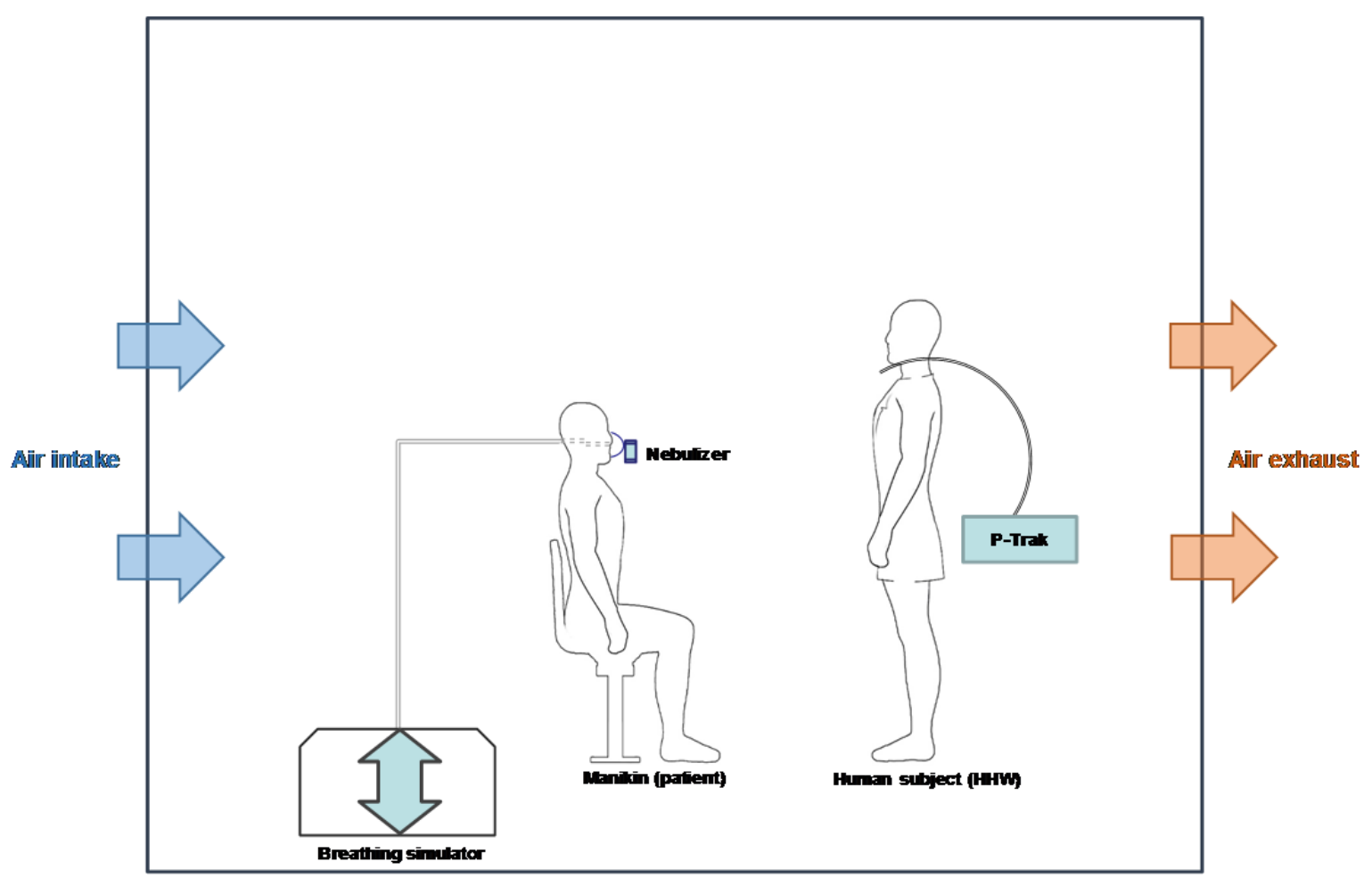

Fig. 1. Schematic diagram of the experimental set-up in the exposure chamber.

A study subject representing an HHW administered the nebulizer treatment to the manikin while standing at different distances from the latter (measured from nose to nose). The four levels of proximity (Table 1) were chosen to represent a working range, including close interaction (6 inches), a typical operational proximity $\left(90^{\circ}\right.$-bent elbow) (12 inches), manipulation of the nebulizer with a stretchedout arm (24 inches), and no manipulation with the nebulizer (the HHW standing 48 inches away).

The air exchange system for the chamber, which included multiple intakes and exhausts (schematically shown as arrows in Fig. 1), was configured so that the HHWrepresenting subject stood downstream from the patientrepresenting manikin. This configuration allowed simulating the worst-case scenario when the aerosol particle transport due to the air exchange enhanced the concentration in the breathing zone of the HHW. The linear air velocity through the chamber, however, was too low $\left(<1 \mathrm{~cm} \mathrm{~s}^{-1}\right)$ to anticipate a sizable flow direction effect on the HHW's aerosol exposure.

The three respiratory protection conditions for the subject included wearing no mask/respirator (an unprotected HHW), wearing a surgical mask (Surgine II, model 4260, Ethicon, Inc., Arlington, TX, USA), and wearing an N95 facepiece filtering respirator (FFR) (3M, model 1860S, Maplewood, MN, USA). The N95 FFR was fit tested prior to wearing with the fit factor passing the OSHA-established threshold of 100 (OSHA, 1999). Two P-Trak condensation particle counters (Model 8525, TSI Inc., Shoreview, MN, USA) were operated in parallel to measure the particle concentration inside $\left(\mathrm{C}_{\mathrm{in}}\right)$ and outside $\left(\mathrm{C}_{\text {out }}\right)$ the mask/respirator when worn. Before testing, the instruments were calibrated against each other. Each trial ran for 5 minutes with three replicates for each study condition. For both types of protection devices, the measured $\mathrm{C}_{\text {out }}$ represented the exposure of an unprotected worker. As $\mathrm{C}_{\text {out }}$ was measured-simultaneously with $\mathrm{C}_{\mathrm{in}}$ - for both respiratory protection devices (three times for each), the total number of replicates for the unprotected HHW was six.

The study protocol was approved by the University of Cincinnati Institutional Review Board (IRB). The informed consent was signed prior to study. After passing a questionnaire-based medical examination, the human subject was cleared to wear an N95 FFR.

\section{Data Analysis}

The particle concentration values measuring the HHW's breathing zone (with and without mask/respirator) using the P-Trak in 6-second time increments were analyzed. The minimum and maximum concentrations across all tested conditions were identified and recorded. The time-weighted average (TWA) values of the aerosol concentration were calculated for each condition over a 5-min runtime (fifty 6second increments). The arithmetic mean and standard deviation were calculated for all replicates.

The Simulated Workplace Protection Factor (SWPF) for both the surgical mask and N95 FFR was determined as a ratio of time-weighted averages of $\mathrm{C}_{\text {out }}$ and $\mathrm{C}_{\text {in }}$ as follows:

$$
S W P F_{T W A}=\frac{\int_{0}^{t} C_{\text {out }}(t) d t}{\int_{0}^{t} C_{\text {in }}(t) d t}
$$


Table 1. A layout of the variables examined in this study. ${ }^{\mathrm{A}}$

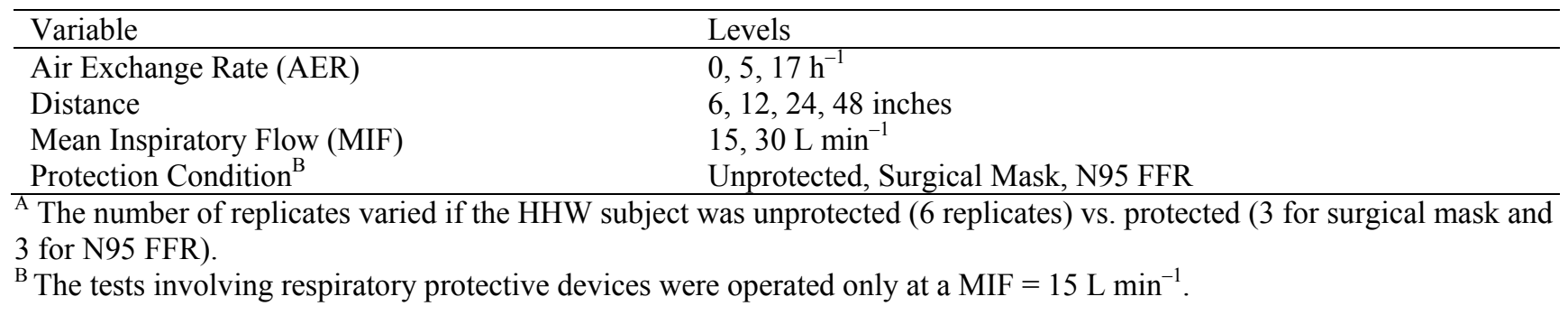

The SWPF data were analyzed and found lognormally distributed. The minimum and maximum SWPF values across all tested conditions were identified and recorded. For each set of conditions (AER, distance, and protective device), the geometric mean (GM) and geometric standard deviation (GSD) were calculated from three 5-min runs.

A mixed effect model was used to compare the variables in this study. This model allowed for the variables to have fixed effects within the same parameters, granting the ability to compare AER, distance, and MIF with their different units. The model was fit to the data obtained for exposure level (represented by the aerosol concentration) and for the SWPF. Accordingly, the effects of the studied factors, such as AER, distance, and MIF were examined. If any factor was found statistically significant, a multiple comparison method (Tukey's contrast test) was performed to look for the differences among multi-levels of each factor and identify the trend in reduction. A p-value of $<0.05$ was considered to be statistically significant. Statistical analysis was performed in R-Studio (version 1.1.447, The R Foundation, New Zealand).

\section{RESULTS AND DISCUSSION}

\section{Unprotected HHW}

The particle concentration values measured in 6-second increments in the breathing zone of an unprotected subject across the entire set of conditions ranged from $7,118 \mathrm{~cm}^{-3}$ to $284,600 \mathrm{~cm}^{-3}$. The concentrations found in this investigation were generally in excess of those measured in the field (Elmashae et al., 2017) (the upper limit was about 5-fold greater) suggesting that this simulation study represents a conservative case. Fig. 2 presents the measurement results. Increase in each of the factors (AER, distance, and MIF) led to the decrease in aerosol exposure. As expected, the aerosol concentration was highest at AER $=0$ and when the HHW was in the closest proximity to the nebulizer outlet. The concentration decrease was less pronounced (with respect to distance) when the AER was 5 or $17 \mathrm{~h}^{-1}$, compared to AER $=0$. The highest level of data variation was found for the 6-inch distance because the particle dispersion via the manikin exhalation introduced variability that was much more evident within closer proximity.

The effect of AER, distance, and MIF on the inhalation aerosol exposure of an HHW was significant $(\mathrm{p}<0.001)$, as shown in Table 2. The mixed effect model revealed that the AER in the chamber was the most significant factor reducing the particle concentration. AER was 5-fold more effective than the proximity, and 4-fold more effective than MIF. In fact, with the introduction of fixed AER, such as 5 or $17 \mathrm{~h}^{-1}$, the distance and MIF were no longer significant $(p>0.05)$. In addition, an increase of AER from 5 to $17 \mathrm{~h}^{-1}$ did not provide the same substantial reduction as seen when AER increased from 0 to $5 \mathrm{~h}^{-1}$. This suggests that an introduction of air exchange as little as $5 \mathrm{~h}^{-1}$ could significantly reduce the aerosol exposure of an $\mathrm{HHW}$ in a home environment, and it may not be necessary to establish an AER as high as the one used in hospital operating rooms (e.g., $17 \mathrm{~h}^{-1}$ ) to effectively decrease the inhalation exposure risk. Fig. 3 demonstrates the concentration reduction as AER is increased.

Based on Tukey's contrast test, proximity to the source had the most substantial effect on the particle concentration in the HHW's breathing zone only when there was no air exchange. The particle concentration decrease with the distance was significant $(\mathrm{p}<0.001)$ but appeared less pronounced as the distance increased beyond 24 inches. Therefore, the benefit of distance from the source of the nebulizer-aerosolized medication diminishes because of the air dilution factor. When the chamber was ventilated $\left(\mathrm{AER}=5\right.$ and $\left.17 \mathrm{~h}^{-1}\right)$, the overall concentration in the environment was approximately one-tenth the level measured with no ventilation, and the distance did not appear to affect the concentration as much (Fig. 2). However, the concentration decreased significantly whenever the distance increased with two exceptions: (1) between 6 and 12 inches $\left(\mathrm{AER}=5 \mathrm{~h}^{-1}, \mathrm{MIF}=15 \mathrm{~L} \mathrm{~min}^{-1}\right)$; and (2) between 12 and 24 inches $\left(\right.$ AER $\left.=17 \mathrm{~h}^{-1}, \mathrm{MIF}=30 \mathrm{~L} \mathrm{~min}^{-1}\right)$. The estimated effect of distance on particle concentration in a ventilated environment was much lower than that with no ventilation. Therefore, in a well-ventilated room, increasing the distance to the patient may not be an effective way to substantially reduce the exposure level. It is acknowledged that this also depends upon how the ventilation system is configured.

These findings are generally consistent with our pilot study (Elmashae et al., 2018) that utilized a more simplistic approach for assessing the aerosol particle concentrations during nebulizer use at distances of 6,12 , and 21 inches from the source involving two manikins and no air exchange factor.

Similar to distance, the patient's MIF significantly reduced particle concentration $(p<0.001)$ as was shown by the comparison of the data obtained at 15 and $30 \mathrm{~L} \mathrm{~min}^{-1}$, but only had a substantial effect when there was no ventilation present. However, this finding can be at least partially attributed to the experimental design, and not 

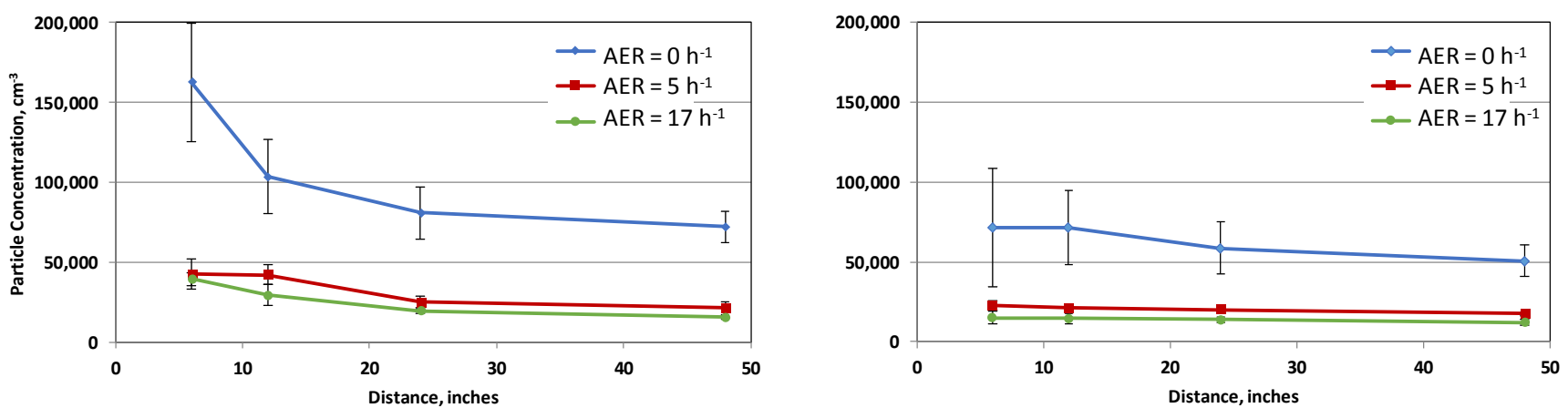

Fig. 2. The effect of the HHW's proximity to the patient-manikin (distance) and of the AER on the aerosol particle concentration in the HHW's breathing zone at manikin's MIF of (Right) $15 \mathrm{~L} \mathrm{~min}^{-1}$ and (Left) $30 \mathrm{~L} \mathrm{~min}^{-1}$. Each data point represents an arithmetic mean and standard deviation of six measurements.

Table 2. Statistical results of the Mixed Effect Model involving the Air Exchange Rate (AER), Distance, Mean Inspiratory Flow (MIF) rate and their interactions.

\begin{tabular}{llllll}
\hline Environmental Factors & Estimated Effect Value & Std. Error & Degrees of Freedom & t-value & p-value \\
\hline Intercept & 12.786709 & 0.06811332 & 8675 & 187.72701 & 0.0000 \\
AER & -0.208143 & 0.01371614 & 8675 & -15.17502 & 0.0000 \\
DISTANCE & -0.037332 & 0.00134901 & 8675 & -27.67400 & 0.0000 \\
MIF & -0.052838 & 0.00133073 & 8675 & -39.70609 & 0.0000 \\
AER:DISTANCE & 0.000983 & 0.00062669 & 8675 & 1.56883 & 0.1167 \\
AER:MIF & 0.000032 & 0.00069705 & 8675 & 0.04645 & 0.9630 \\
DISTANCE:MIF & 0.000918 & 0.00006275 & 8675 & 14.62228 & 0.0000 \\
AER:DISTANCE:MIF & 0.000005 & 0.00002895 & 8675 & 0.17399 & 0.8619 \\
\hline
\end{tabular}

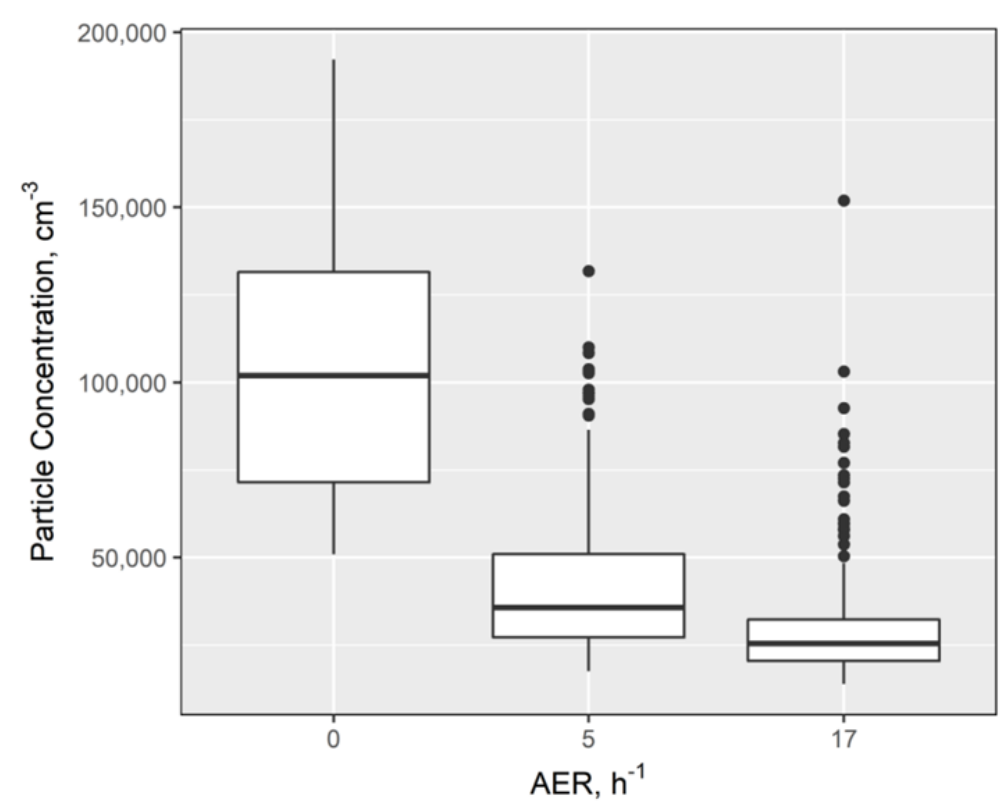

Fig. 3. The effect of AER on the aerosol particle concentration while the subject stood at 12 inches and manikin's MIF was $15 \mathrm{~L} \mathrm{~min}^{-1}$. The increase of the AER from 0 to $5 \mathrm{~h}^{-1}$ decreased the particle concentration most significantly.

necessarily to the effect of MIF per se. As a HEPA filter was placed between the breathing simulator and the manikin's breathing line, more particles were naturally drawn onto the filter at $30 \mathrm{~L} \mathrm{~min}^{-1}$ compared to $15 \mathrm{~L} \mathrm{~min}^{-1}$, thus decreasing the overall aerosol concentration in the environment. Additionally, increase in MIF improves the air mixing around the manikin and enhances the evaporation of the nebulizer-generated droplets. We visually observed a dense cloud at MIF $=15 \mathrm{~L} \mathrm{~min}^{-1}$ around the nebulizer mask, which essentially disappeared (or got diluted) once the flow rate was increased to $30 \mathrm{~L} \mathrm{~min}^{-1}$. This likely affected the aerosol concentration in the room and, 
consequently, the particle concentration that we measured in the breathing zone of the healthcare worker. An increase in MIF during a fixed ventilation rate was statistically significant, but the estimated effect was of much lower magnitude compared to the effect of ventilation.

\section{Protected $\mathrm{HHW}$}

When the subject was wearing the surgical mask, the particle concentrations measured in 6-second increments inside the mask across the entire set of conditions ranged from 58 to $128,400 \mathrm{~cm}^{-3}$, and the values of $\mathrm{SWPF}_{\mathrm{TWA}}$ varied from $\mathrm{GM}=2.58(\mathrm{GSD}=1.23)$ to $\mathrm{GM}=6.55(\mathrm{GSD}$ $=1.16$ ) (Fig. 4). Thus, the surgical mask provided low respiratory protection, which is consistent with findings of numerous studies (Chen and Willeke, 1992; Rengasamy et al., 2004; Grinshpun et al., 2009; Booth et al., 2013; He et al., 2013; Gao et al., 2016; Grinshpun et al., 2016; Elmashae et al., 2017). It should be noted that a surgical mask was never intended to be an effective respiratory protective device for the wearer, but was designed to reduce exposure of others to the wearer-released particles. There was no consistent significant trend in which the AER and distance affected the SWPF of the surgical mask.

The particle concentrations inside the N95 FFR obtained in 6-second increments ranged from 32 to $7,324 \mathrm{~cm}^{-3}$, and the $\mathrm{SWPF}_{\mathrm{TWA}}$ varied from $\mathrm{GM}=62.1(\mathrm{GSD}=1.21)$ to $\mathrm{GM}=101.6$ (GSD = 1.13) (Fig. 4). No significant effect of either distance or AER was identified $(\mathrm{p}>0.05)$. An HHW wearing an N95 FFR will be significantly $(\mathrm{p}<0.001)$ better protected than an individual wearing a surgical mask (Fig. 4). The respiratory protection improvement was on average around 20 -fold.

The SWPFs of the surgical mask tested in the present simulation study were comparable to workplace protection factors obtained in the field investigation of Elmashae et al. (2017) that was conducted in a real home healthcare environment with different working tasks including a nebulizer treatment; the SWPFs of the tested N95 FFR were somewhat higher than the field measured values. The difference may be attributed to various reasons, e.g., the fact that the subject in our study was less active than the actual workers performing multiple tasks in a home; consequently, less intense body movement helped maintain the respirator fit resulting in higher measured SWPF.

Among all factors affecting the aerosol exposure of an HHW tested in this investigation, wearing an N95 FFR was the most effective means for exposure reduction.

\section{CONCLUSIONS}

This simulation study suggests that for an unprotected HHW administering nebulizer-aerosolized medications, some form of ventilation (air exchange) is the most effective way of reducing aerosol exposure. This ventilation does not have to be as effective as in a hospital room; an AER of $5 \mathrm{~h}^{-1}$ could be sufficient to significantly reduce the exposure risk. Proximity to the aerosol source matters, but its effect diminishes once the distance increases beyond 24 inches.

The SWPF offered by a surgical mask was significantly lower than that of the N95 FFR, as expected. Among all the factors affecting the aerosol exposure of an HHW that were tested in this investigation, wearing an N95 was the most effective way to reduce exposure. Therefore, an HHW should consider wearing an N95 FFR during home visits to decrease the risk of exposure to nebulized medications. We fall short, however, of claiming that N95-grade FFRs adequately protect an HHW from these hazards or identifying a specific level of respiratory protection that must be achieved. This is because no permissible exposure limits have been established for most of the medications delivered by medical nebulizers. We note that other types of control (e.g., source control) may be as effective as or even more effective than respiratory protection-for

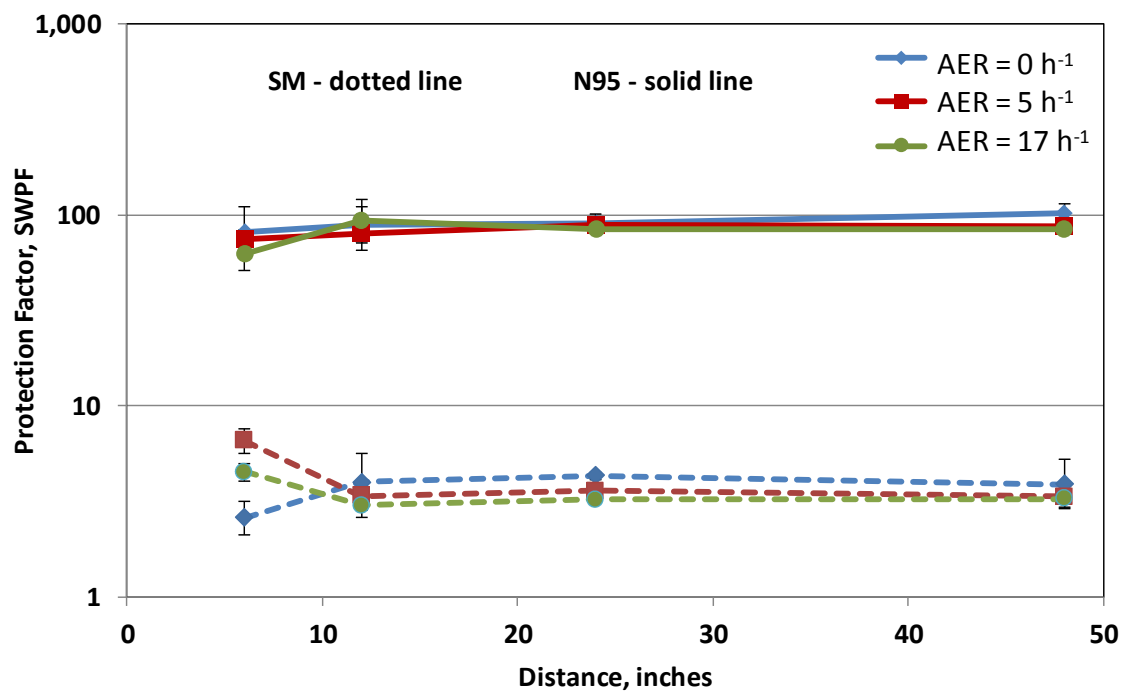

Fig. 4. SWPFs of the surgical mask (SM) and the N95 FFR determined at different HHW's proximities to the aerosol source and different air exchange conditions. The patient-manikin's MIF was $15 \mathrm{~L} \mathrm{~min}{ }^{-1}$. Each data point represents an arithmetic mean and standard deviation of three measurements. 
instance, a better-designed nebulizer delivery system that reduces fugitive aerosol exposure may help minimize the release of aerosol into the environment and thus reduce healthcare workers' exposure to medications-but these alternatives were not examined in our study.

It is acknowledged that while the present study considerably expanded the scope of our earlier investigation (Elmashae et al., 2018), it is still a simulation study and, as such, has limitations. Future investigations should be conducted in homes to improve the assessment of HHWs' exposure to aerosolized medications delivered by different nebulizers as well as to other aerosol hazards, which, in turn, will help us to better understand the potential role of respiratory protective devices in controlling the aerosol exposure of these workers.

\section{FUNDING}

This research study was supported by the National Institute for Occupational Safety and Health through the Targeted Research Training Program of the University of Cincinnati Education and Research Center Grant \#T42OH008432.

\section{REFERENCES}

Agbonifo, N., Hittle, B., Suarez, R. and Davis, K. (2017). Occupational exposures of home healthcare workers. Home Healthc. Now 35: 150-159.

Ari, A., Fink, J.B. and Pilbeam, S. (2016). Secondhand aerosol exposure during mechanical ventilation with and without expiratory filters: An in-vitro study. Indian $J$. Resp. Care. 5: 677-682.

ASHRAE (2017). Standard 170-2017: Ventilation of health care facilities (ANSI/ASHRAE/ASHE Approved). ASHRAE Standards and Guidelines, www.ashrae.org.

Barrett, K.E., Barman, S., Boitano, S. and Brooks, H. (2012). Ganong's review of medical physiology, $24^{\text {th }}$ Ed., McGraw-Hill Education, New York, USA.

Bone, W.D. and Amundson, D.E. (1993). An unusual case of severe anaphylaxis due to Ipratropium Bromide inhalation. Chest 103: 981-982.

Booth, C.M., Clayton, M., Crook, B. and Gawn J.M. (2013). Effectiveness of surgical masks against influenza bioaerosols. J. Hosp. Infect. 82: 22-26.

Campbell, S. (1999). For COPD a combination of ipratropium bromide and albuterol sulfate is more effective than albuterol base. Arch. Intern. Med. 159: 156-160.

Chen, C.C. and Willeke, K. (1992). Aerosol penetration through surgical masks. Am. J. Infect. Control 20: 177184.

Elmashae Y., Yermakov, M., Frank, E., Michael, B., Maier, A., Newman, N., Reponen, T. and Grinshpun, S.A. (2018). Exposure of home-attending healthcare workers to aerosolized medications (Simulation study). J. Aerosol Sci. [Submitted].

Elmashae, Y., Grinshpun, S.A., Reponen, T., Yermakov, M. and Riddle, R. (2017). Performance of two respiratory protective devices used by home-attending health care workers (a pilot study). J. Occup. Environ. Hyg. 14: 145-149.

Gao, S., Koehler, R.H., Yermakov, M., Gao, S., Grinshpun, S.A. and Koehler, R.H. (2016). Performance of facepiece respirators and surgical masks against surgical smoke: Workplace protection factor study. Ann. Occup. Hyg. 60: 608-618.

Gershon, R.R., Magda, L.A., Canton, A.N., Riley, H.E., Wiggins, F., Young, W. and Sherman, M.F. (2010). Pandemic-related ability and willingness in home healthcare workers. Am. J. Disaster Med. 5: 15-26.

Gershon, R.R., Pogorzelska, M., Qureshi, K.A., Stone, P.W., Canton, A.N., Samar, S.M., Westra, L.J., Damsky, M.R. and Sherman, M. (2008). Home health care patients and safety hazards in the home: Preliminary findings. In Advances in patient safety: New directions and alternative approaches, vol. 1, Henriksen, K., Battles, J.B., Keyes, M.A. and Grady, M.L. (Ed.), Agency of Health Research and Quality, Rockville, MD, USA.

Grinshpun, S.A., Gao, S., Yermakov, M., Elmashae, Y., Reponen, T. and Koehler, R. (2016). Surgical smoke aerosol: Exposure assessment and respiratory protection. Presented at the Abstracts of the European Aerosol Conference, September 4-9, 2016, Tours, France.

Grinshpun, S.A., Haruta, H., Eninger, R.M., Reponen, T., McKay, R.T. and Lee, S.A. (2009). Performance of an N95 filtering facepiece particulate respirator and a surgical mask during human breathing: Two pathways for particle penetration. J. Occup. Environ. Hyg. 6: 593603.

He, X., Reponen, T., McKay, R.T. and Grinshpun, S.A. (2013). Effect of particle size on the performance of an N95 filtering facepiece respirator and a surgical mask at various breathing conditions. Aerosol Sci. Technol. 47: 1180-1187.

Jayaraman, D. and Brar, K. (2016). A case of Ipratropium Bromide allergy in a patient with severe persistent asthma. Ann. Allergy Asthma Immunol. 117: S22.

Kerwin, E.M., Taveras, H., Iverson, H., Wayne, D., Shah, T., Lepore, M.S. and Miller, D.S. (2016). Pharmacokinetics, pharmacodynamics, efficacy, and safety of albuterol (salbuterol) multi-dose dry-powder inhaler and ProAir ${ }^{\circledR}$ hydrofluoroalkane for the treatment of persistent asthma: Results of two randomized double-blind studies. Clin. Drug Investig. 36: 55-65.

Lawson, C.C., Rocheleau, C.M., Whelan, E.A., Lividoti Hibert, E.N., Grajewski, B., Spiegelman, D. and RichEdwards, J.W. (2012). Occupational exposures among nurses and risk of spontaneous abortion. Am. J. Obstet. Gynecol. 206: 327.e1-327.e8.

Lindh, W.Q., Pooler, M., Tamparo, C. and Dahl, B.M. (2009). Delmar's comprehensive medical assisting: administrative and clinical competencies ( $4^{\text {th }}$ Edition), Cengage Learning, Clifton Park, NY, USA, p. 573.

Nicklas, R.A. (1990). Paradoxical bronchospasm associated with the use of inhaled beta agonists. J. Allergy Clin. Immunol. 85: 959-964.

OSHA (1999). Respiratory protection. U.S. Government Printing Office, Office of the Federal Register, 
Washington, DC. Code of Federal Regulation Title 29, Part 1910.134.

Reichman, R., Shirazi, E., Colliver, D.G. and Pennell, K.G. (2017). US residential building air exchange rate: new perspectives to improve decision making at vapor intrusion sites. Environ. Sci. Processes Impacts 19: 87100.

Rengasamy, A., Zhuang, Z. and Berryann, R. (2004). Respiratory protection against bioaerosols: literature review and research needs. Am. J. Infect. Control 32: 345-354.

Riordan, T.G. and Smaldone, G.C. (1992). Exposure of health care workers to aerosolized pentamidine. Chest 101: 1494-1499.

Rodríguez-Molinero A., Narvaiza, L., Ruiz, J. and GálvezBarrón, C. (2013). Normal respiratory rate and peripheral blood oxygen saturation in the elderly population. $J$. Am. Geriatrics Soc. 61: 2238-2240.

Sherman, M.F., Gershon, R.R.M., Samar, S.M., Pearson, J.M., Canton, A.N. and Damsky, M.R. (2008). Safety factors predictive of job satisfaction and job retention among home healthcare aides. J. Occup. Environ. Med. 50: 1430-1441.

Vecchio, D., Sasco, A.J. and Cann, C.I. (2003). Occupational risk in health care and research. Am. J. Ind. Med. 43: 369-397.

Received for review, October 12, 2018

Revised, December 7, 2018

Accepted, December 10, 2018 